\title{
Social media use in patients with fibromyalgia and its effect on symptom severity and sleep quality
}

\author{
Sevinç Külekçioğlu ${ }^{*}$ (1) and Alp Çetin ${ }^{2}$ (1)
}

\begin{abstract}
Background: The aim of this study was to evaluate social media use in patients with fibromyalgia syndrome (FMS) and determine the effect of social media use on disease severity and sleep quality.

Materials and methods: In total, 205 social media using patients with similar characteristics were included in the study. The study group consisted of 103 patients with FMS, and the control group consisted of 102 patients without FMS. The FMS symptom severity scale and diffuse pain index were used to determine the disease severity in FMS patients, the sleep disorder short form questionnaire (PROMIS) was used to evaluate sleep quality, and the Social Media Addiction Scale-Adult Form was used to evaluate social media addiction. A visual analog scale was applied to evaluate pain in both the patient and control groups, and social media usage times were recorded.
\end{abstract}

Results: We found that pain severity, sleep disturbance and social media addiction were higher in patients with FMS than in the control group, and there was no relationship between the rates of social media use in patients with FMS and the severity and prevalence of the disease.

Conclusion: The use of social media is more frequent in patients with FMS, which can motivate healthcare professionals to evaluate social media habits in individuals with FMS.

Keywords: Fibromyalgia, Social media, Addiction, Sleep disorders, Pain, Problematic social media use

\section{Introduction}

Fibromyalgia syndrome (FMS) is a chronic disease characterized by widespread, permanent musculoskeletal system pain accompanied by symptoms such as fatigue, sleep disorders, depression, anxiety, and cognitive disorders [1]. In a recent study, the prevalence of FMS was found to be $0.2-6.6 \%$ in the general population and $2.4-6.8 \%$ in females [2]. Because of its symptoms, FMS has been found to affect daily functions both physically and psychologically $[3,4]$. FMS may be seen together with various psychiatric disorders. The prevalence of emotional

\footnotetext{
*Correspondence: sevinckulek@gmail.com

${ }^{1}$ Physical Medicine and Rehabilitation, City Hospital, Bursa, Turkey

Full list of author information is available at the end of the article
}

problems is high, and anxiety disorders, depression, and sleep disorders often accompany FMS [5-9]. Poor sleep has been reported by approximately $80 \%$ of FMS patients [10]. Epidemiological studies have shown that poor sleep quality is a risk factor for fibromyalgia, and poor sleep has been associated with the severity of symptoms in the fibromyalgia population $[11,12]$.

Information technology in the form of computers and the internet has entered every area of life and is increasingly spreading throughout the world $[13,14]$. The implementation of the internet and internet-linked applications on mobile devices and communication systems, not just computers, has transformed people of all ages from passive users into individuals producing active content [14]. According to Internet World Statistics (2017) research, the number of internet users has reached approximately 
3 billion, 732 million (49.6\%) worldwide [14]. Social media applications have been highlighted as the most commonly used feature of the internet [15]. According to Turkish Statistics Institution data (TUIK, 2016), the rate of internet users in Turkey is $61.2 \%$ of the population; of these, $82.4 \%$ use social media $[13,14]$. There are various reasons for the high use of social media, such as establishing communication with people, publishing personal posts, following local and international news, learning, researching, and enjoyment [15-17]. It is also thought that people use social media to increase their self-confidence and to be able to share their thoughts and feelings $[16,18]$. However, it has been emphasized that, as social media use increases, there is an increased risk of social media addiction and psychopathological symptoms [1921]. Social media addiction is seen as a behavioral addiction that includes active interaction [22]. While there is an association between routine social media use and positive health outcomes, excessive use of social media has been found to be associated with depressive symptoms, anxiety, and sleep disorders [19-21, 23]. The frequent observation of anxiety, sleep disorders and depressive symptoms in FMS patients suggests that social media use may be different in FMS patients. To the best of our knowledge, there has been no previous study in the literature on the social media use of FMS patients. Against this background, the aim of the present study is not to discuss the true nature of excessive social media use but rather to address the widespread social media agenda in terms of pain and sleep disturbance. Here we emphasize the need to seek a new perspective to keep in mind when examining harmful aspects.

In this study, we aimed to evaluate the use of social media by FMS patients and determine its effect on disease severity and sleep disorders.

\section{Patients and methods}

This prospective, cross-sectional study was conducted in the Physical Medicine and Rehabilitation (PMR) Clinic of Bursa City Hospital. Overall, 205 social media user patients were included in the study. The study group included 103 patients aged $>18$ years who presented at the PMR clinic and were diagnosed with FMS according to the 2016 ACR revised diagnostic criteria [24]. These patients diagnosed with FMS were treated for anxiety, sleep disturbance or depression for at least 3 months. The control group consisted of 102 patients who presented to the PMR outpatient clinic with a complaint of pain for at least 3 months, had not received any psychiatric treatment in the last 3 months, had no history of anxiety or depression, and had not been diagnosed with FMS. Patients were excluded from the study if they had a malignant disease, any central or peripheral neurological disease, cognitive problems, severe systemic disease, severe degenerative changes, or an educational level that would prevent them from completing the questionnaire. All patients' data, such as sex, educational status, marital status, occupation, age, height, weight, and body mass index (BMI), were recorded. The length of stay on social media (SSM) was recorded in minutes/day $(\mathrm{min} / \mathrm{d})$. The visual analog scale (VAS) was used to assess pain severity. The VAS is a common, simple method with robust validity and reliability. The physician explained the meaning of each number to the patients on a scale of $10 \mathrm{~cm}$ $(\mathrm{cm})$ and asked them to mark the severity of pain. For the evaluation of sleep in all the study participants, the Patient Reported Outcomes Measurement Information System (PROMIS) 8-item sleep disorder short form questionnaire was used [25]. This self-reported form evaluates, and scores sleep quality, sleep depth, adequacy, and satisfaction with sleep in the last 7 days. To evaluate social media addiction, the Social Media Addiction Scale-Adult Form (SMAS-AF) was used, which was developed by Şahin and Yağci [14]. Before completing the form, all patients with and without FMS were informed about which applications were included in social media use (Facebook, Instagram, Twitter, and YouTube). The SMAS-AF comprises 20 items in 2 subdimensions (virtual tolerance and virtual communication), which are answered with 5-point Likert-type responses. The virtual tolerance subdimension comprises items 1-11, and the virtual communication subdimension comprises items 12-20. Item number 5 and 11 are scored in reverse. The 5 -point scoring is applied as "(1) Definitely not appropriate," "(2) Not appropriate," “(3) Undecided," “(4) Appropriate" and "(5) Quite appropriate." Negative statements are reverse-scored. The maximum points obtained from the scale range from 20 to 100 , with high points indicating that the individual perceives themselves to have social media addiction. To determine the disease severity in FMS patients, the FMS symptom severity scale and the widespread pain index were used [24]. The total score was recorded by adding the scores obtained from this scale and index. Recording the general characteristics of the patients, age, height, weight, BMI, and SSM time measurements were made and recorded by a specialist doctor. Questionnaires were filled out by the patients.

\section{Statistical analysis}

In the study, the descriptive statistics of the patients were given as the means and standard deviations, and the Shapiro Wilk test was used to examine the assumption of normality of the measurements. According to the results, nonparametric methods were used because the number of groups was small, and the test results were appropriate. The Mann-Whitney U test and Kruskal-Wallis test 
were performed to examine the measurements in groups. The chi-square test was used to examine the differences in patient characteristics according to study groups, and the Spearman correlation test was used to examine the relationships between patient measurements and disease scores. In the study, $p$ values less than 0.05 were considered statistically significant $(\alpha=0.05)$. Analyses were finalized with the help of the SPSS 25.0 package program.

\section{Results}

The general characteristics of 205 patients participating in the study are shown in Table 1, and the measurement results are shown in Table 2. The time spent on social media was longer in patients in the FMS group; the measured VAS score, PROMIS Sleep score and SMAF score values were higher than those in the control group (Table 3) (Fig. 1); and there was no difference in the distribution of general characteristics and measurements between the FMS and control groups (Table 4). The analysis of the relationship between FMS disease severity and patient characteristics in the FMS group is shown in Table 5. Table 6 shows the analysis of the relationship between SSM duration, PROMIS sleep score, SMAF score and patient characteristics in the FMS group. Students were found to spend more time on social media than other professions. The evaluation of the relationship between patient characteristics and scores is shown in Table 7. In both groups, the relationship between the age of the patients and SSM duration was weak and inversely proportional, whereas the time spent on social media decreased as age increased. The relationship between the scores according to patient group is shown in Table 8.

Table 1 Examination of general characteristics of patients

\begin{tabular}{llll}
\hline Patient characteristics & Category & $\mathbf{n}$ & $\mathbf{n} \%$ \\
\hline Group & FMS & 103 & 50.2 \\
Gender & Control & 102 & 49.8 \\
& Male & 182 & 88.8 \\
Education & Female & 23 & 11.2 \\
& Primary & 97 & 47.3 \\
\multirow{3}{*}{ Marital Status } & High school & 64 & 31.2 \\
& University & 44 & 21.5 \\
Occupation & Married & 176 & 85.9 \\
& Single & 29 & 14.1 \\
& Housewife & 93 & 45.4 \\
& Worker & 56 & 27.3 \\
& Desk job & 34 & 16.6 \\
& Student & 8 & 3.9 \\
& Retired & 14 & 6.8 \\
\hline
\end{tabular}

Table 2 Analysis of patient measurements

\begin{tabular}{lc}
\hline Measurement & Mean \pm SD \\
\hline Age & $44.75 \pm 11.19$ \\
Height & $162.9 \pm 7.56$ \\
Weight & $72.02 \pm 13.02$ \\
BMI & $27.15 \pm 4.75$ \\
SSM duration (min/day) & $103.83 \pm 86.51$ \\
VAS score & $4.61 \pm 2.02$ \\
PROMIS sleep score & $21.18 \pm 11.04$ \\
SMAF score & $39.11 \pm 11.23$ \\
FMS score & $16.08 \pm 3.86$ \\
\hline
\end{tabular}

$S D$ standard deviation

\section{Discussion}

In this study, we evaluated the social media usage of FMS patients and investigated the effect of this on disease severity and sleep quality. The detected VAS score, PROMIS sleep score and SMAS score were higher in patients with FMS than in the control group, and pain severity, sleep disturbance and social media addiction were higher in patients with FMS. Although studies in the literature have shown a relationship between intense social media use and depression, anxiety, and sleep disorders, to the best of our knowledge [21, 23, 26], no study has investigated social media use in FMS patients. Depression, anxiety, and sleep problems are often seen in FMS patients, and this may be associated with more intense social media use. In this study, significantly more social media use was found in FMS patients, but interestingly, no relationship was found between the rates of social media use in patients with FMS and the severity or prevalence of the disease. These data suggest that social media use is more associated with the abovementioned symptoms accompanying FMS rather than the symptom severity and extent of FMS. Social media use may be

Table 3 Analysis of patient measurements according to groups

\begin{tabular}{lccc}
\hline Measurement & \multicolumn{2}{l}{ Group } & $p$ \\
\cline { 2 - 3 } & FMS & \\
& Mean \pm SD & Mean \pm SD & \\
\hline Age & $44.37 \pm 9.63$ & $45.13 \pm 12.61$ & 0.62 \\
Height & $162.29 \pm 6.79$ & $163.51 \pm 8.24$ & 0.25 \\
Weight & $71.5 \pm 1.3$ & $72.55 \pm 12.77$ & 0.56 \\
BMI & $27.16 \pm 4.98$ & $27.15 \pm 4.53$ & 0.98 \\
SSM duration & $153.2 \pm 93.95$ & $53.97 \pm 34.73$ & $0.01^{*}$ \\
VAS score & $5.16 \pm 2.03$ & $4.06 \pm 1.85$ & $0.01^{*}$ \\
PROMIS sleep score & $27.31 \pm 8.61$ & $14.98 \pm 9.71$ & $0.01^{*}$ \\
SMAF score & $44.56 \pm 11.23$ & $33.6 \pm 8.14$ & $0.01^{*}$ \\
\hline${ }^{*} p<0.05$ significant difference & &
\end{tabular}




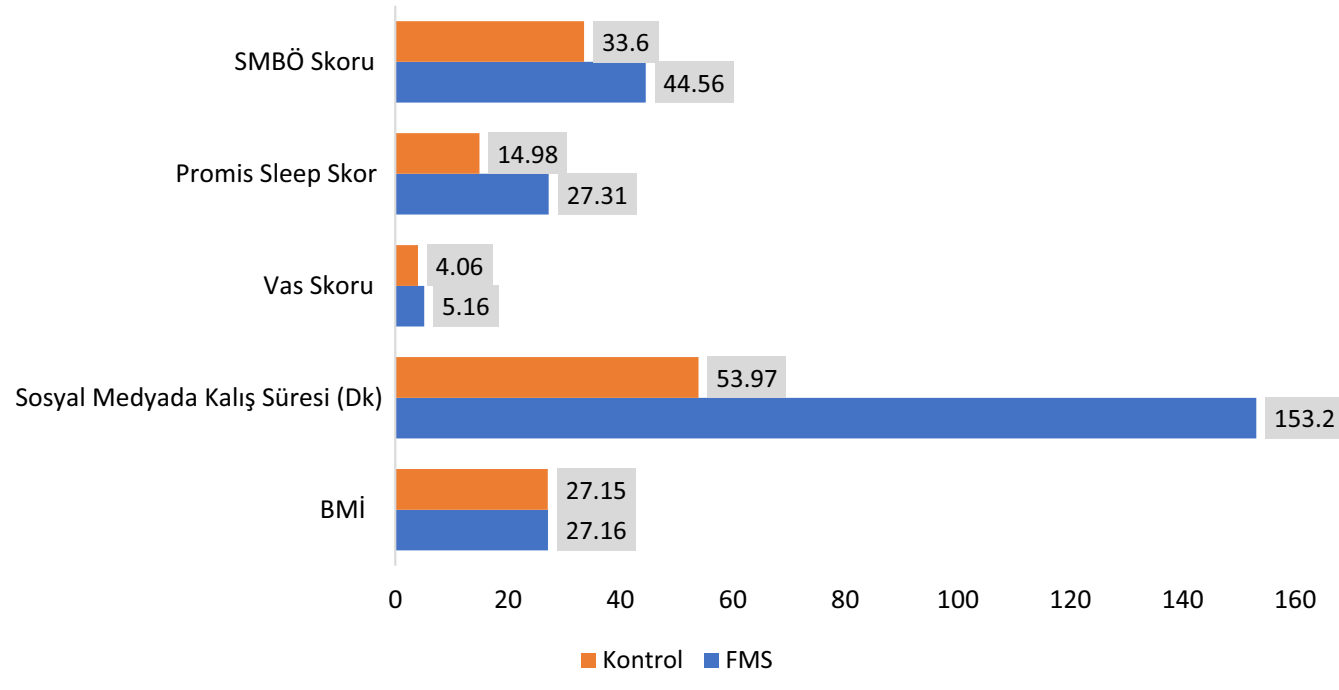

Fig. 1 Analysis of patient measurements according to groups

Table 4 Analysis of general characteristics of patients according to groups

\begin{tabular}{|c|c|c|c|c|c|}
\hline \multirow{3}{*}{$\begin{array}{l}\text { General } \\
\text { characteristics of } \\
\text { patients }\end{array}$} & \multicolumn{4}{|c|}{ Group } & \multirow[t]{3}{*}{$p$} \\
\hline & \multicolumn{2}{|c|}{ FMS } & \multicolumn{2}{|c|}{ Control } & \\
\hline & $\mathrm{n}$ & $\mathrm{n} \%$ & $\mathrm{n}$ & $\mathrm{n} \%$ & \\
\hline \multicolumn{6}{|l|}{ Gender } \\
\hline Male & 93 & 90.3 & 89 & 87.3 & \multirow[t]{2}{*}{0.49} \\
\hline Female & 10 & 9.7 & 13 & 12.7 & \\
\hline \multicolumn{6}{|l|}{ Education } \\
\hline Primary & 55 & 53.4 & 42 & 41.2 & \multirow[t]{3}{*}{0.21} \\
\hline High school & 28 & 27.2 & 36 & 35.3 & \\
\hline University & 20 & 19.4 & 24 & 23.5 & \\
\hline \multicolumn{6}{|l|}{ Marital status } \\
\hline Married & 89 & 86.4 & 87 & 85.3 & \multirow[t]{2}{*}{0.89} \\
\hline Single & 14 & 13.6 & 15 & 14.7 & \\
\hline \multicolumn{6}{|l|}{ Occupation } \\
\hline Housewife & 49 & 47.6 & 44 & 43.1 & \multirow[t]{5}{*}{0.82} \\
\hline Worker & 30 & 29.1 & 26 & 25.5 & \\
\hline Desk job & 14 & 13.6 & 20 & 19.6 & \\
\hline Student & 4 & 3.9 & 4 & 3.9 & \\
\hline Retired & 6 & 5.8 & 8 & 7.8 & \\
\hline
\end{tabular}

affected by several factors like as age, gender, marital status, occupation, and educational level. Previous studies have shown that young people are also more likely to use social media due to their easier adaptation to technology and their desire to use technology intensively [27, 28]. Similarly, in this study, a negative relationship was found between age and duration of social media use. When the FMS group was evaluated in terms of occupations,
Table 5 Analysis of the relationship between FMS disease severity and patient characteristics in the FMS group

\begin{tabular}{lll}
\hline Patient characteristics & $\begin{array}{l}\text { FMS disease severity } \\
\text { Mean } \pm \text { SD }\end{array}$ & $p$ \\
\hline Gender & $16.11 \pm 3.7$ & 0.36 \\
Male & $15.9 \pm 5.4$ & \\
Female & & 0.19 \\
Education & $15.49 \pm 3.43$ & \\
Primary & $17.68 \pm 4.94$ & \\
High school & $15.5 \pm 2.59$ & 0.15 \\
University & & \\
Marital status & $15.93 \pm 4.02$ & 0.07 \\
Married & $17.07 \pm 2.56$ & \\
Single & & \\
Occupation & $16.35 \pm 3.64$ & \\
Housewife & $15.27 \pm 4.23$ & \\
Worker & $15.86 \pm 2.44$ & \\
Desk job & $16.00 \pm 2.45$ & \\
Student & $18.67 \pm 6.38$ & \\
Retired &
\end{tabular}

although there was no difference in the SMAF scores of the students, the SSM duration was found to be significantly longer, and this was attributed to the fact that young people and students stay on social media more for entertainment purposes. The fact that the students in the control group had a longer SSM period supports this view. Sleep disorders are commonly seen in FMS. Previous studies have shown that $80 \%$ of FMS patients have sleep disorders $[26,29]$. In accordance with the literature, in this study, there was also an association between 
Table 6 Analysis of the relationship between SSM duration, PROMIS sleep score, SMAF score and patient characteristics in the FMS group

\begin{tabular}{|c|c|c|c|c|c|c|}
\hline & $\begin{array}{l}\text { SSM duration } \\
\text { Mean } \pm \text { SD }\end{array}$ & $\begin{array}{l}\text { PROMIS sleep score } \\
\text { Mean } \pm \text { SD }\end{array}$ & $\begin{array}{l}\text { SMAF score } \\
\text { Mean } \pm \text { SD }\end{array}$ & $p$ ssm & $p$ promis & $p$ smaf \\
\hline \multicolumn{7}{|l|}{ Gender } \\
\hline Male & $104.01 \pm 85.04$ & $21.32 \pm 11.1$ & $38.94 \pm 11.27$ & 0.26 & 0.31 & 0.35 \\
\hline Female & $102.39 \pm 99.51$ & $20 \pm 10.72$ & $40.43 \pm 11.04$ & & & \\
\hline \multicolumn{7}{|l|}{ Education } \\
\hline Primary & $91.24 \pm 67.59$ & $21.68 \pm 11.04$ & $37.62 \pm 11.3$ & 0.09 & 0.23 & 0.41 \\
\hline High school & $118.98 \pm 107.99$ & $21.27 \pm 11.77$ & $40.39 \pm 11.77$ & & & \\
\hline University & $109.55 \pm 86.53$ & $19.93 \pm 10.04$ & $40.52 \pm 10.02$ & & & \\
\hline \multicolumn{7}{|l|}{ Marital status } \\
\hline Married & $98.66 \pm 80.14$ & $21.03 \pm 10.87$ & $38.88 \pm 11.39$ & 0.0 & 0.42 & 0.38 \\
\hline Single & $135.17 \pm 114.9$ & $22.03 \pm 12.18$ & $40.52 \pm 10.27$ & & & \\
\hline \multicolumn{7}{|l|}{ Occupation } \\
\hline Housewife & $89.19 \pm 73$ & $21.1 \pm 11.03$ & $37.52 \pm 11.02$ & $0.01^{*}$ & 0.12 & 0.22 \\
\hline Worker & $106.7 \pm 90.53$ & $22.32 \pm 11.34$ & $40.57 \pm 11.39$ & & & \\
\hline Desk job & $113.24 \pm 77.79$ & $21.32 \pm 10.24$ & $40.5 \pm 10.22$ & & & \\
\hline Student & $215.63 \pm 142.06$ & $17.38 \pm 11.6$ & $46.13 \pm 9.93$ & & & \\
\hline Retired & $102.86 \pm 96.65$ & $18.93 \pm 12.21$ & $36.43 \pm 13.46$ & & & \\
\hline
\end{tabular}

${ }^{*} p$ value ranges from 0.01 to 0.05 ; there is a statistically significant difference

Table 7 Determination of the relationship between patient characteristics and scores

\begin{tabular}{|c|c|c|c|c|c|c|c|}
\hline Group & Measurement & & SSM duration & VAS score & $\begin{array}{l}\text { PROMIS sleep } \\
\text { score }\end{array}$ & SMAF score & FMS disease score \\
\hline \multirow[t]{8}{*}{ FMS } & \multirow[t]{2}{*}{ Age } & r & $-0.296^{* *}$ & 0.014 & 0.133 & -0.015 & -0.162 \\
\hline & & $p$ & 0.012 & 0.972 & 0.182 & 0.884 & 0.102 \\
\hline & \multirow[t]{2}{*}{ Height } & r & 0.145 & -0.032 & -0.012 & 0.157 & 0.015 \\
\hline & & $p$ & 0.145 & 0.751 & 0.983 & 0.112 & 0.957 \\
\hline & \multirow[t]{2}{*}{ Weight } & r & -0.017 & -0.055 & 0.044 & 0.081 & 0.015 \\
\hline & & $p$ & 0.868 & 0.581 & 0.662 & 0.414 & 0.881 \\
\hline & \multirow[t]{2}{*}{ BMI } & r & -0.080 & -0.054 & 0.058 & 0.016 & -0.018 \\
\hline & & $p$ & 0.423 & 0.586 & 0.558 & 0.871 & 0.936 \\
\hline \multirow[t]{8}{*}{ Control } & \multirow[t]{2}{*}{ Age } & r & $-0.246^{* *}$ & 0.066 & -0.132 & -0.120 & \\
\hline & & $p$ & 0.013 & 0.511 & 0.187 & 0.231 & \\
\hline & \multirow[t]{2}{*}{ Height } & r & -0.043 & -0.047 & 0.045 & 0.106 & \\
\hline & & $p$ & 0.670 & 0.650 & 0.657 & 0.290 & \\
\hline & \multirow[t]{2}{*}{ Weight } & $r$ & -0.142 & -0.053 & -0.045 & -0.093 & \\
\hline & & $p$ & 0.155 & 0.597 & 0.653 & 0.353 & \\
\hline & \multirow[t]{2}{*}{ BMl } & r & -0.135 & 0.104 & -0.087 & -0.163 & \\
\hline & & $p$ & 0.176 & 0.297 & 0.382 & 0.102 & \\
\hline
\end{tabular}

**The $r$ correlation coefficient is significant

symptom severity and sleep disorders in FMS patients [30-32]. The relationship between sleep and pain is twoway; patients may sleep badly because of pain, or pain may increase because of poor sleep [33]. In the current study, consistent with these data, sleep disorders were found at a higher rate in FMS patients than in the control group. Furthermore, in the FMS patients with greater sleep disorders, the FMS disease severity and pain scores were determined to be higher. Interestingly, contrary to previous studies, this study did not find a significant relationship between sleep disorders and social media addiction [34-36]. This may be because previous studies 
Table 8 Determination of the relationship between scores according to patient groups

\begin{tabular}{|c|c|c|c|c|c|c|c|}
\hline Group & & & SSM duration & VAS score & $\begin{array}{l}\text { PROMIS sleep } \\
\text { score }\end{array}$ & SMAF score & $\begin{array}{l}\text { FMS } \\
\text { disease } \\
\text { score }\end{array}$ \\
\hline \multirow[t]{10}{*}{ FMS } & SSM duration & $r$ & 1 & & & & \\
\hline & & $p$ & & & & & \\
\hline & VAS score & r & 0.10 & 1 & & & \\
\hline & & $p$ & 0.34 & & & & \\
\hline & PROMIS sleep score & r & 0.07 & $0.196^{*}$ & 1 & & \\
\hline & & $p$ & 0.49 & 0.05 & & & \\
\hline & SMAF score & r & $0.537^{* *}$ & 0.03 & -0.03 & 1 & \\
\hline & & $p$ & 0.01 & 0.78 & 0.74 & & \\
\hline & FMS disease score & r & -0.03 & $0.277^{* *}$ & $0.278^{* *}$ & 0.01 & \\
\hline & & $p$ & 0.74 & 0.01 & 0.01 & 0.99 & \\
\hline \multirow[t]{8}{*}{ Control } & SSM duration & r & 1 & & & & \\
\hline & & $p$ & & & & & \\
\hline & VAS score & r & 0.05 & 1 & & & \\
\hline & & $p$ & 0.65 & & & & \\
\hline & PROMIS sleep score & r & 0.07 & -0.03 & 1 & & \\
\hline & & $p$ & 0.51 & 0.73 & & & \\
\hline & SMAF score & r & $0.414^{* *}$ & -0.18 & -0.02 & 1 & \\
\hline & & $p$ & 0.01 & 0.07 & 0.87 & & \\
\hline
\end{tabular}

**The $r$ correlation coefficient is significant

included people who did not have FMS or any disease and found that excessive social media use causes sleep disturbance. In addition, it is thought that the sleep disorder seen in FMS is not the result of social media use but is related to the natural course of the disease. There were some limitations to this study. For example, it was cross-sectional, and the scales were completed by the patients. Although it is easy to obtain descriptive data in a cross-sectional study, it is difficult to determine cause and effect relationships. FMS patients with anxiety, depression or sleep disturbances were investigated and not compared with FMS patients without these complaints. The time period in which the networks were most used was not analyzed. In addition, the social media addiction scale used in this study is not a questionnaire of international use that has been tried and used previously in these types of studies. Nevertheless, this questionnaire was used, as it was developed for the Turkish population, was in the Turkish language, and had been subjected to validity and reliability studies.

\section{Conclusions}

Social media use was found to be higher in patients with FMS. As a result, although there was significantly more social media use in FMS, no relationship was found between the rates of social media use and the severity or prevalence of the disease in patients with FMS. These data suggest that social media use is more associated with symptoms accompanying FMS than with symptom severity and prevalence of FMS. As causality factors continue to be explored, these insights can motivate healthcare professionals to evaluate social media habits in individuals with FMS. As the first study to investigate the relationship between social media use and FMS, it can be considered that the study will serve as a guide for future more detailed studies.

\section{Acknowledgements \\ Not applicable.}

Authors' contributions

KS conceived the study, performed data collection, analysis, review, and interpretation, and drafted the manuscript. CA analysis, review and interpretation and contributed to the writing of the manuscript. The authors read and approved the final manuscript.

Funding

Not applicable.

Availability of data and materials

The datasets used and/or analyzed during the current study are available from the corresponding author on reasonable request.

\section{Declarations}

Ethics approval and consent to participate

This study was approved by the Research Ethics Committee of the institution (decision no: 2011-KAEK-25 2019/12-18) and was conducted in accordance 
with the Declaration of Helsinki. Participants were included after written informed consent was obtained.

\section{Consent for publication}

Not applicable.

\section{Competing interests}

The authors declare that they have no competing interests.

\section{Author details}

${ }^{1}$ Physical Medicine and Rehabilitation, City Hospital, Bursa, Turkey. ${ }^{2}$ Faculty of Medicine, Physical Medicine and Rehabilitation, Hacettepe University, Ankara, Turkey.

\section{Received: 26 May 2021 Accepted: 14 August 2021}

Published online: 23 August 2021

\section{References}

1. Wolfe F, Smythe HA, Yunus MB, Bennett RM, Bombardier C, et al. The American College of Rheumatology 1990 criteria for the classification of fibromyalgia. Report of the multicenter criteria committee. Arthritis Rheum. 1990:33:160-72. https://doi.org/10.1002/art.1780330203.

2. Marques AP, Santo ASE, Berssaneti AA, Matsutani LA, Yuan SLK. Prevalence of fibromyalgia: literature review update. Revista Brasileira de Reumatologia (English Edition). 2017;57:356-63. https://doi.org/10.1016/j.rbre.2017.01.005.

3. Romano GF, Tomassi S, Russell A, Mondelli V, Pariante CM. Clinical challenges in the biopsychosocial interface. Adv Psychosom Med. 2015;34:61-77. https://doi.org/10.1159/000369085.

4. Dailey DL, Keffala VJ, Sluka KA. Do cognitive and physical fatigue tasks enhance pain, cognitive fatigue, and physical fatigue in people with fibromyalgia? Arthritis Care Res. 2015;67:288-96. https://doi.org/10.1002/acr.22417.

5. Berkol TD, Balcioglu YH, Kirlioglu SS, Erensoy H, Vural M. Dissociative features of fibromyalgia syndrome. Neurosciences (Riyadh). 2017;22:198-204. https:// doi.org/10.17712/nsj.2017.3.20160538.

6. Sluka KA, Clauw DJ. Neurobiology of fibromyalgia and chronic widespread pain. Neuroscience. 2016;338:114-29. https://doi.org/10.1016/j.neuroscience. 2016.06 .

7. Santos Dde M, Lage LV, Jabur EK, Kaziyama HHS, losifescu DV, et al. The association of major depressive episode and personality traits in patients with fibromyalgia. Clinics (Sao Paulo). 2011;66:973-8. https://doi.org/10.1590/ S1807-59322011000600009.

8. Salazar A, Dueñas M, Mico JA, Ojeda B, Agüera-Ortiz L, et al. Undiagnosed mood disorders and sleep disturbances in primary care patients with chronic musculoskeletal pain. Pain Med. 2013;14(9):1416-25. https://doi.org/10.1111/ pme.12165.

9. Aguglia A, Salvi V, Maina G, Rossetto I, Aguglia E. Fibromyalgia syndrome and depressive symptoms: comorbidity and clinical correlates. J Affect Disord. 2011;128:262-6. https://doi.org/10.1016/j.jad.2010.07.004

10. Wu YL, Chang LY, Lee HC, Fang SC, Tsai PS. Sleep disturbances in fibromyalgia. A meta-analysis of case-control studies. J Psychosom Res. 2017;96:89-97. https://doi.org/10.1016/j.jpsychores.2017.03.011.

11. Écija C, Luque-Reca O, Suso-Ribera C, Catala P, Peñacoba C. Associations of cognitive fusion and pain catastrophizing with fibromyalgia impact through fatigue, pain severity, and depression: an exploratory study using structural equation modeling. J Clin Med. 2020;9:1763. https://doi.org/10.3390/jcm90 61763.

12. Choy EHS. The role of sleep in pain and fibromyalgia. Nat Rev Rheumatol. 2015;11(9):513-20. https://doi.org/10.1038/nrrheum.2015.56.

13. Duggan M, Ellison NB, Lampe C, Lenhart A, Madden M. Social media update 2014: while Facebook remains the most popular site, other platforms see higher rates of growth. Washington: Pew Research Center; 2015.

14. Şahin C, Yağcı M. Social media addiction scale-adult form: the reliability and validity study. J Ahi Evran Univ Kırşehir Fac Educ. 2017;18(1):523-38.

15. Demirci I. The adaptation of the Bergen Social Media Addiction Scale to Turkish and its evaluation of relationship with depression and anxiety symptoms. Anatol J Psychiatry. 2019;20:15-22.

16. Fox S, Rainie $H$. The web at 25 in the US. [Internet \& American Life Project]. Washington: Pew Research Center; 2014.
17. Subrahmanyam K, Reich SM, Waechter N, Espinoza G. Online and offline social networks: use of social networking sites by emerging adults. J Appl Dev Psychol. 2008;29:420-33. https://doi.org/10.1016/j.appdev.2008.07.003.

18. Lim MS, Choi SB. Stress caused by social media network applications and user's responses. Multimed Tools Appl. 2017;76:17685-98. https://doi.org/10. 1007/s11042-015-2891-z.

19. van den Eijnden RJJM, Lemmens JS, Valkenburg PM. The social media disorder scale: validity and psychometric properties. Comput Human Behav. 2016:61:478-87. https://doi.org/10.1016/j.chb.2016.03.038.

20. Lee-Won RJ, Herzog L, Park SG. Hooked on Facebook: the role of social anxiety and need for social assurance in problematic use of Facebook. Cyberpsychol Behav Soc Netw. 2015;18:567-74. https://doi.org/10.1089/cyber.2015. 0002.

21. Mohammadbeigi A, Absari R, Valizadeh F, Saadati M, Sharifimoghadam S, et al. Sleep quality in medical students; the impact of over- use of mobile cellphone and social networks. J Res Health Sci. 2016;16:46-50.

22. Griffiths M. Behavioral addiction: an issue for everybody? Empl Couns Today. 1996:3:19-25

23. Pantic I, Damjanovic A, Todorovic J, Topalovic D, Bojovic-Jovic D, et al. Association between online social networking and depression in high school students: behavioral physiology viewpoint. Psychiatr Danub. 2012;24:90-3.

24. Yanmaz MN, Atar S, Biçer M. The reliability and validity of the Turkish version of fibromyalgia survey diagnostic criteria and symptom severity scale. J Back Musculoskelet Rehabil. 2016;29:287-93. https://doi.org/10.1136/annrh eumdis-2015-eular.2026.

25. Yu L, Buysse DJ, Germain A, Moul DE, Stover A, et al. Development of short forms from the PROMIS ${ }^{\mathrm{TM}}$ sleep disturbance and Sleep-Related Impairment item banks. Behav Sleep Med. 2011;10:6-24. https://doi.org/10.1080/15402 002.2012 .636266

26. Sharma MK, John N, Sahu M. Influence of social media on mental health: a systematic review. Curr Opin Psychiatry. 2020;33:467-75. https://doi.org/10. 1097/YCO.0000000000000631.

27. Lenhart A, Ling R, Campell S, Purcell K. Teens, and mobile phones. Washington: Pew Internet and American Life Project; 2010.

28. Turel $\mathrm{O}$, Alexander $\mathrm{S}$. The benefits and dangers of enjoyment with social networking websites. Eur J Inf Syst. 2012;21:512-28. https://doi.org/10.1057/ ejis.2012.1.

29. Bennett RM, Jones J, Turk DC, Russell IJ, Matallana L. An internet survey of 2596 people with fibromyalgia. BMC Musculoskelet Disord. 2007;8:27.

30. Mork PJ, Nilsen TI. Sleep problems and risk of fibromyalgia: Iongitudinal data on an adult female population in Norway. Arthritis Rheum. 2012;64:281-4. https://doi.org/10.1002/art.33346.

31. Andrade A, Vilarino GT, Sieczkowska SM, Coimbra DR, Bevilacqua GG, et al. The relationship between sleep quality and fibromyalgia symptoms. J Health Psychol. 2020;25:1176-86. https://doi.org/10.1177/1359105317751615.

32. Jacobson SA, Simpson RG, Lubahn C, Hu C, Belden CM, et al. Characterization of fibromyalgia symptoms in patients 55-95 years old: a longitudinal study showing symptom persistence with suboptimal treatment. Aging Clin Exp Res. 2015;27(1):75-82. https://doi.org/10.1007/s40520-014-0238-7.

33. Podsakoff PM, MacKenzie SB, Lee JY, Podsakoff NP. Common method biases in behavioral research: a critical review of the literature and recommended remedies. J Appl Psychol. 2003;88:879-903.

34. Malaeb D, Salameh P, Barbar S, Awad E, Haddad C, et al. Problematic social media use and mental health (depression, anxiety, and insomnia) among Lebanese adults: any mediating effect of stress? Perspect Psychiatr Care. 2021;57(2):539-49. https://doi.org/10.1111/ppc.12576.

35. Lin CY, Imani V, Griffiths MD, Broström A, Nygårdh A, et al. Temporal associations between morningness/eveningness, problematic social media use, psychological distress, and daytime sleepiness: mediated roles of sleep quality and insomnia among young adults. J Sleep Res. 2021;30(1):13076. https://doi. org/10.1111/jsr.13076.

36. Montag C, Hegelich S. Understanding detrimental aspects of social media use: will the real culprits please stand up? Front Sociol. 2020;5:599270. https:// doi.org/10.3389/fsoc.2020.599270.

\section{Publisher's Note}

Springer Nature remains neutral with regard to jurisdictional claims in published maps and institutional affiliations. 